\title{
LRP6 is involved in the proliferation, migration and invasion of trophoblast cells via miR-346
}

\author{
LU ZHANG, HUIHUI LI, MINGBAO LI, WENXIA ZHANG, ZHOU YANG and SHUQUAN ZHANG
}

\begin{abstract}
Department of Obstetrics and Gynecology, Qilu Hospital of Shandong University, Jinan, Shandong 250012, P.R. China
\end{abstract}
Received August 2, 2019; Accepted December 18, 2019

DOI: $10.3892 / \mathrm{ijmm} .2020 .4570$

\begin{abstract}
Low-density lipoprotein receptor-related protein 6 (LRP6) promotes metastasis in numerous types of cancer; however, its role in trophoblast cells has been less frequently reported. In the present study, the effects of up- and downregulation of LRP6 on trophoblast cells were investigated accordingly. The study aimed to develop a therapeutic target for gestational choriocarcinoma. The expression levels of LRP6 in pre-eclampsia (PE) tissues, trophoblast cell lines and gestational choriocarcinoma cells were determined using reverse transcription-quantitative polymerase chain reaction (RT-qPCR) assay. Double-luciferase reporter analysis was conducted to detect the regulatory gene of LRP6. Furthermore, the proliferative, migratory and invasive abilities of trophoblasts and gestational choriocarcinoma cells were determined by CCK-8, wound healing, and Transwell assays, respectively. The expression levels of the genes and proteins of interest [matrix metalloproteinase (MMP)-2, MMP-9, tissue inhibitor of metalloproteinase-1 (TIMP-1), and TIMP-2] associated with tumor cell invasion were measured by performing RT-qPCR and western blotting, respectively. The National Center for Biotechnology Information database revealed that LRP6 was relatively highly expressed in placental tissues, but was poorly expressed in PE tissues and trophoblast cell lines. The upregulation of LRP6 not only increased the activity, migration and invasion of trophoblast cells, but it also promoted the expression of MMP-2 and MMP-9, whereas it inhibited the expression levels of TIMP-1 and TIMP-2. Such results followed the opposite trend to those of downregulation of LRP6 in gestational choriocarcinoma cells. Moreover, LRP6 was predicted to be the target gene for microRNA (miR)-346, which was highly expressed in PE tissues and trophoblast cell lines. The present study also revealed that LRP6 could reverse the effects of miR-346 on the proliferation, migration and invasion of trophoblast cells. Therefore, considered
\end{abstract}

Correspondence to: Dr Shuquan Zhang, Department of Obstetrics and Gynecology, Qilu Hospital of Shandong University, 107 Wenhuaxi Road, Jinan, Shandong 250012, P.R. China

E-mail: zhangshuquan0326@126.com

Key words: pre-eclampsia, trophoblast cells, low-density lipoprotein receptor-related protein 6 , proliferation, migration, invasion collectively, the results of the present study have demonstrated that LRP6 is involved in the proliferation, migration and invasion of trophoblast cells via miR-346, and that LRP6 may serve as a potential target in cancer treatment.

\section{Introduction}

Hypertensive disorders emerge during pregnancy, including gestational hypertension, pre-eclampsia (PE), eclampsia, chronic hypertension complicated with PE, and chronic hypertension (1). $\mathrm{PE}$, which is mainly characterized by maternal proteinuria and hypertension, is one of the main causes of maternal and perinatal mortality $(2,3)$. The morbidity rate due to PE is increasing, although the etiology and pathogenesis of PE are not fully understood; therefore, clinical treatment strategies available to treat the disease are currently limited (4). According to the latest published articles, the proliferation, invasion and migration of trophoblast cells into the uterus serve important roles in human placenta formation and embryo implantation $(5,6)$. Decreased invasive ability, and increased apoptosis, of trophoblast cells are two major causes of PE during the critical stage of placental implantation (7). Once certain changes in the regulatory factors have taken place, trophoblast cells will greatly proliferate and develop into choriocarcinoma, which causes damage to the tissues and blood vessels surrounding the uterus, and distant metastasis at an early stage. Therefore, regulating the proliferation, migration and invasion of trophoblast cells has a positive significance for the treatment of PE and related diseases.

Previous studies $(8,9)$ have highlighted that the oxidation of low-density lipoprotein (LDL) leads to upregulation of the levels of inflammatory factors, including tumor necrosis factor- $\alpha$ and interleukin- 6 , in the body, and may decrease the cell invasive ability of trophoblasts and promote cell apoptosis, thereby resulting in abnormal development of placenta and the occurrence of PE. According to the National Center for Biotechnology Information (NCBI) database, LDL receptor-related protein 6 (LRP6) is highly expressed in placental tissues. Previous studies have confirmed that LRP6 serves a critical role in promoting the migration and invasion of numerous types of cancers; for example, Liu et al (10) reported that LRP6 is upregulated in breast cancer tissues, and that its overexpression is an important factor contributing to cancer cell migration and invasion. Therefore, it was possible to hypothesize that LRP6 may be involved in regulating the migration and invasive abilities of trophoblast cells. 
The current study aimed to determine the expression levels of LRP6 in PE tissues and trophoblast cell lines, to explore the effects of upregulated and downregulated LRP6 on the proliferation, migration and invasion of trophoblast cells, and to further probe the relevant targets and mechanisms. Furthermore, the mechanism of migration and invasion of trophoblast cells was also explored so as to provide a probable therapeutic target for the treatment of PE and other related diseases.

\section{Materials and methods}

Participants. A total of 40 patients diagnosed with PE (11) who attended the Qilu Hospital of Shandong University from January to December 2018 were enrolled for the present study. The patients were pregnant and primipara, aged between 24 and 29 years old, and their gestational ages ranged from 34-39 weeks. Patients receiving reproductive technical assistance, a history of repeated abortions and pregnancy complications (such as hypertension, gestational diabetes and/or heart disease) were excluded. As healthy controls, 22 corresponding normal pregnant women were selected for comparison, whose characteristics were similar to those of the patients with PE in terms of their gestational age and body mass index. All participants underwent cesarean sections. The study was approved by the Ethics Committee of Qilu Hospital of Shandong University (grant approval number: SDUQLH20180121), and written informed consent was obtained from all participants.

Tissue acquisition. Tissue masses measuring $1 \mathrm{x} 1 \mathrm{x} 1 \mathrm{~cm}$ were collected within 3 min after the delivery of placenta by Cesarean section (avoiding bleeding, infarction and calcification areas). Extracted tissues were dried using a dry gauze, frozen in liquid nitrogen, and stored in a refrigerator at $-70^{\circ} \mathrm{C}$. All the above procedures were performed under aseptic conditions. The relationship between LRP6 and placental tissue was assessed using the NCBI database (https://www.ncbi.nlm.nih. gov/gene/4040).

Cell culture. The trophoblast cell line B6Tert-1 was purchased from the Institute of Zoology, State Key Laboratory of Reproductive Biology, Chinese Academy of Sciences, and the trophoblast cell line HTR8/SVneo was obtained from American Type Culture Collection (ATCC). The gestational choriocarcinoma cell line JEG-3 (also purchased from ATCC) served as a control.B6Tert-1 cells were cultured in InvitrogenF12/Dulbecco's modified Eagle's medium (DMEM; 1:1) containing $2 \mathrm{mmol} / \mathrm{l}$ glutamine, $10 \mathrm{mg} / \mathrm{ml}$ insulin, $10 \mathrm{ng} / \mathrm{ml}$ epidermal growth factor, and $0.1 \%$ bovine serum albumin (Invitrogen; Thermo Fisher Scientific, Inc.). HTR8/SVneo and JEG-3 cells were maintained in Gibco Roswell Park Memorial Institute (RPMI)-1640 medium (Thermo Fisher Scientific, Inc.) that contained $100 \mu \mathrm{g} / \mathrm{ml}$ streptomycin, 100 units/ml penicillin (Invitrogen; Thermo Fisher Scientific, Inc.), and 10\% HyClone $^{\mathrm{TM}}$ fetal bovine serum (GE Healthcare Life Sciences). All the cells were incubated in a humidified environment at $37^{\circ} \mathrm{C}$ under an atmosphere of $5 \% \mathrm{CO}_{2}$, and the medium was changed daily.

Cell transfection. To investigate the effects of LRP6 on trophoblast cells, the LRP6 sequence were synthesized by Guangzhou RiboBio
Co., Ltd. and cloned into the pcDNA3.1 vector (cat. no. V79020; Thermo Fisher Scientific, Inc.). siLRP6 (20 pmol; cat. no. \#8650, Cell Signaling Technology, Inc.) was transfected into JEG-3 cells ( $3 \times 10^{5}$ cells), whereas the HTR8/SVneo cell line ( $3 \times 10^{5}$ cells) was transfected with the LRP6 overexpression plasmid (20 pmol) using Invitrogen Lipofectamine ${ }^{\circledR} 2000$ transfection reagent (Thermo Fisher Scientific, Inc.). For comparison, untransfected cells served as blank controls, whereas JEG-3 cells transfected with scrambled sequence served as a negative control (siNC; 20 pmol; cat. no. 1022076; Qiagen, Inc.). The siNC sequence was: Sense, 5'-UUCUCCGAACGUGUCACGU-3' and antisense, 5'-ACGUGACACGUUCGGAGAA-3'. HTR8/SVneo cells were transfected with an empty pcDNA3.1 vector $(20 \mathrm{pmol})$ as the mock group.

In order to explore the role of microRNA (miRNA/miR)-346 in JEG-3 and HTR8/SVneo cells, 20 pmol mimics control (cat. no. 4464059; Thermo Fisher Scientific, Inc.), miR-346 mimics (cat. no. 4464066; Thermo Fisher Scientific, Inc.), inhibitor control (cat. no. 4464079; Thermo Fisher Scientific, Inc.), and miR-346 inhibitor (cat. no. HLTUD0507; Sigma-Aldrich; Merck KGaA) were respectively transfected into the two cell lines using Lipofectamine ${ }^{\circledR} 2000$ transfection reagent. JEG-3 cells ( $3 \times 10^{5}$ cells) were co-transfected with 20 pmol siLRP6 and 20 pmol miR-346 inhibitor, whereas HTR8/SVneo cells ( $3 \times 10^{5}$ cells) were co-transfected with 20 pmol LRP6 and 20 pmol miR-346 mimics. In addition, 20 pmol inhibitor control and 20 pmol siNC were co-transfected into JEG-3 cells ( $3 \times 10^{5}$ cells), and HTR8/SVneo cells $\left(3 \times 10^{5}\right.$ cells) were co-transfected with mimics control and empty pcDNA3.1 vector (mock), and served as negative controls for comparison. In the cell transfection process, $2 \mu 1$ Lipofectamine ${ }^{\circledR} 2000$ reagent were mixed with 50 pmol RNA to generate liposome-enclosed nucleotides.

Reverse transcription-quantitative polymerase chain reaction (RT-qPCR) assay. Total RNA from tissues and cells was isolated using Invitrogen reagent (Thermo Fisher Scientific, Inc.), and the quality and integrity of the total RNAs were analyzed using a NanoDrop ${ }^{\mathrm{TM}}$ 2000c spectrophotometer (Thermo Fisher Scientific, Inc.) and 1\% modified agarose gel electrophoresis. First-strand cDNA was synthesized from the isolated RNA $(1 \mu \mathrm{g})$ using PrimeScript RT Master mix (Perfect Real-Time) (Takara Bio Inc.), according to the manufacturer's protocol. The RT-qPCR assay was performed using an ABI Prism 7500 Fast Real-time PCR system (Applied Biosystems; Thermo Fisher Scientific, Inc.), and the thermocycling reaction conditions were set as follows: 40 cycles at $50^{\circ} \mathrm{C}$ for $10 \mathrm{~min}$ and $95^{\circ} \mathrm{C}$ for $10 \mathrm{~min}$, then $95^{\circ} \mathrm{C}$ for $15 \mathrm{sec}$ and $45^{\circ} \mathrm{C}$ for $45 \mathrm{sec}$. The corresponding mRNA expression levels were normalized against the expression of $\beta$-actin or U6, and the data were processed using the comparative $2^{-\Delta \Delta \mathrm{Cq}}$ method (12). The primers were synthesized by Shanghai GenePharma Co., Ltd., and their sequences are shown in Table I.

Cell Counting Kit-8(CCK-8) assay. Viability of the transfected cells was determined using a CCK- 8 kit (Beyotime Institute of Biotechnology). In brief, after transfection had been allowed to proceed for 24 and $48 \mathrm{~h}, 10 \mu \mathrm{lCCK}-8$ reagents were added into the transfected cells and co-cultured at $37^{\circ} \mathrm{C}$ under an atmosphere of $5 \% \mathrm{CO}_{2}$ for $2 \mathrm{~h}$. The optical density (OD) values of 
Table I. Primer sequences.

\begin{tabular}{lll}
\hline Gene & \multicolumn{1}{c}{ Forward (5'-3') } & \multicolumn{1}{c}{ Reverse $\left(5^{\prime}-3^{\prime}\right)$} \\
\hline LRP6 & TTGTTGCTTTATGCAAACAGACG & CGTTTAATGGCTTCTTCGCTGAC \\
miR-346 & GATGCTATGTCTGCCCGCAT & ATACCAACAAGTGCTGAGGAAGTG \\
MMP-2 & GTGATCTTGACCAGAATACC & GCCAATGATCCTGTATGTG \\
MMP-9 & AAGGATGGGAAGTACTGG & GCCCAGAGAAGAAGAAAG \\
TIMP-1 & CACCTTATACCAGCGTTATG & TTTCCAGCAATGAGAAACTC \\
TIMP-2 & GGCCTGATAAGGATATAGAG & CTTTCCTGCAATGAGATATTCC \\
$\beta$-actin & CCAACCGCGAGAAGATGA & CCAGAGGCGTACAGGGATAG \\
U6 & CTCGCTTCGGCAGCACA & AACGCTTCACGAATTTGCGT
\end{tabular}

LRP6, low-density-lipoprotein receptor-related protein 6; MMP, matrix metalloproteinase; TIMP, tissue inhibitor of metalloproteinase.

the cells were measured using an ELX800 BioTek microplate reader (Biotek Instruments, Inc.) at $450 \mathrm{~nm}$, and the OD values of the cells was measured at 24, 48, 72 and $96 \mathrm{~h}$, respectively.

Wound-healing assay. The migration distances of the transfected cells were measured by performing a wound-healing assay. For detection, and prior to the assay, the transfected cells were cultured in serum-free medium in 24-well plates to reach $90-100 \%$ confluence. A $200 \mu \mathrm{l}$ sterile pipette tip was used to scratch a wound through the cells; subsequently, the wounds were observed, and images were captured, under an inverted microscope (Eclipse TS-100; Nikon Corporation) at 0 and $24 \mathrm{~h}$.

Transwell invasion assay. The invasive abilities of the transfected cells were determined using Costar ${ }^{\mathrm{TM}}$ Transwell invasion chambers (Corning Inc.). In the experiment, the upper chambers were pre-coated with Matrigel ${ }^{\mathrm{TM}}$ (BD Biosciences), whereas the lower chambers contained the medium with $10 \%$ FBS. The transfected cells $\left(3 \times 10^{5} / \mathrm{ml}\right)$ were suspended in serum-free medium, and transferred into the upper chamber (200 $\mu \mathrm{l} /$ well). After incubation for $24 \mathrm{~h}$, non-invaded cells were removed by cotton swabs, whereas the invaded cells were fixed in $4 \%$ paraformaldehyde and stained with $0.1 \%$ crystal violet solution for $20 \mathrm{~min}$. The invaded cells were observed and counted under an inverted microscope (Eclipse TS-100; Nikon Corporation).

Western blot (WB) analysis. WB analysis was performed to detect the expression levels of proteins of interest in the cells. Total proteins were extracted using RIPA lysis buffer (Beijing Solarbio Science \& Technology Co., Ltd.), and the concentrations of proteins were determined using a bicinchoninic acid (BCA) protein assay (Pierce; Thermo Fisher Scientific, Inc.). Total proteins $(50 \mu \mathrm{g})$ were separated by SDS-PAGE (Beyotime Institute of Biotechnology) using 10\% gels, and then transferred onto a polyvinylidene difluoride (PVDF) membrane (Merck Millipore). After blocking the membranes with 5\% non-fat milk for $1 \mathrm{~h}$, the membranes were co-cultured with primary antibodies [anti-LRP6 (1:2,000; cat. no. ab134146), anti-MMP-2 (1:1,000; cat. no. ab37150), anti-MMP-9 (1:1,000; cat. no. ab73734), anti-TIMP-1 (1:500; cat. no. ab61224), anti-TIMP-2 (1:500; cat. no. ab180630) all antibodies purchased from Abcam] overnight at $4^{\circ} \mathrm{C} ; \beta$-actin
(1:5,000; cat. no. ab8226; Abcam) was used as the internal reference. Subsequently, homologous secondary antibodies [rabbit anti-mouse IgG H\&L (HRP), cat. no. ab3728, 1:7,000; and goat anti-rabbit IgG H\&L (HRP), cat. no. ab6721, 1:7,000; both from Abcam] were added and incubated with the membranes for $2 \mathrm{~h}$ at $37^{\circ} \mathrm{C}$. The protein blots were developed using ECL detection reagent (cat. no. 345818; Merck Millipore) and scanned using a sensitive multifunctional imager (Amersham Imager 600; GE Healthcare).

Double-luciferase reporter analysis. LRP6 was shown to be the potential target for miR-346 using TargetScan 7.2 (http://http://www.targetscan.org/) as the prediction method, which was subsequently verified by double-luciferase reporter analysis. For the assay experiment, either the wild-type or the mutant sequence of the LRP6 3'-untranslated region (3'-UTR) was inserted into the reporter plasmid (Promega Corporation) to construct the corresponding carriers. miR-346 mimics and blank control were respectively co-transfected into HTR8/SVneo and JEG-3 cells containing the constructed carriers with wild-type and mutant LRP6 3'-UTR for $48 \mathrm{~h}$ using Lipofectamine ${ }^{\mathrm{TM}} 2000$ transfection reagent. The luciferase activity of the cells was determined by using the Luciferase Assay systems of Promega, following the manufacturer's protocol (Promega Corporation).

Statistical analysis. Statistical Package of the Social Sciences 20.0 software (SPSS, Inc.) was used for data analysis. The data are shown as the mean \pm standard deviation (SD). Comparisons between groups were performed by Student's t-test or one-way analysis of variance (ANOVA) followed by post hoc test (Tukey's). All experiments were repeated in triplicate. $\mathrm{P}<0.05$ was considered to indicate a statistically significant value.

\section{Results}

Expression of LRP6 is decreased in trophoblast cells. The NCBI database (https://www.ncbi.nlm.nih.gov/gene/4040) revealed that LRP6 was relatively highly expressed in placental tissues (Fig. 1A). In the current study, the RT-qPCR results revealed that the expression level of LRP6 in placental tissues derived from patients with PE was measurably reduced compared with that in normal pregnant women 

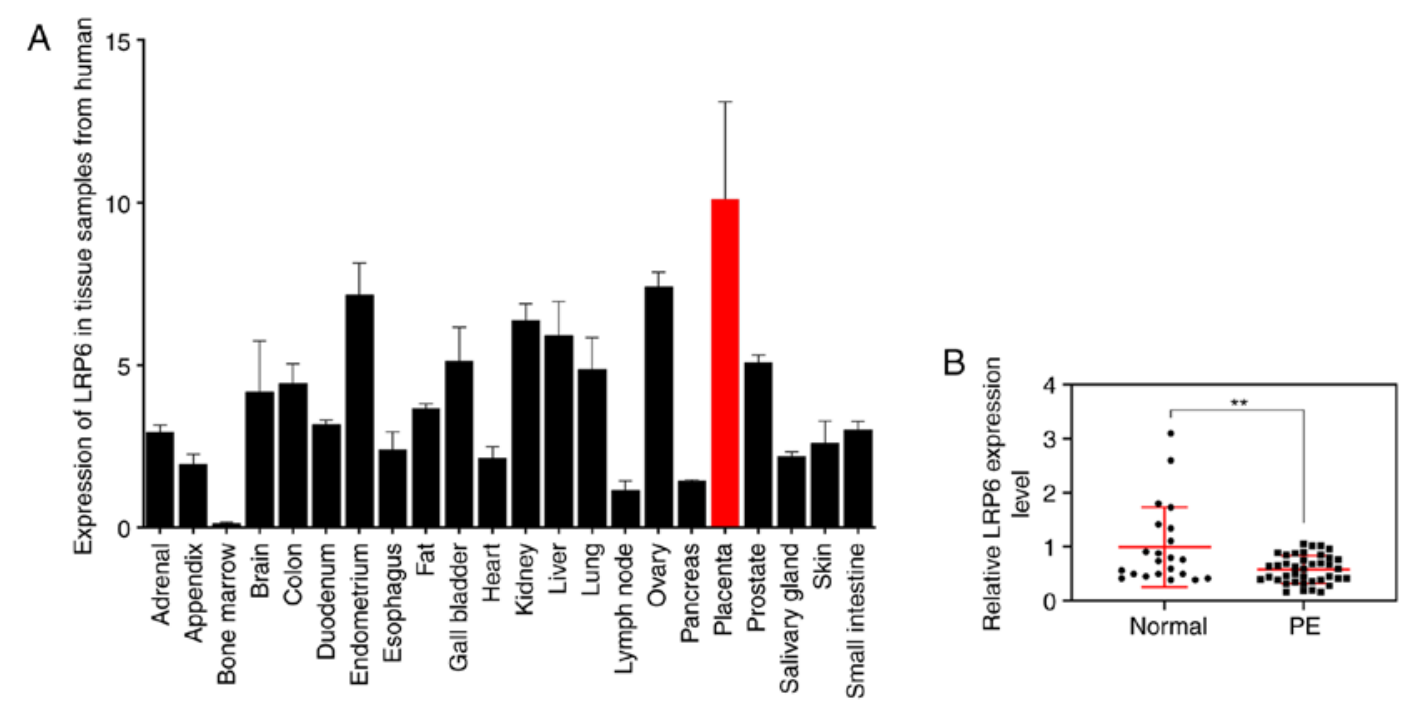

C
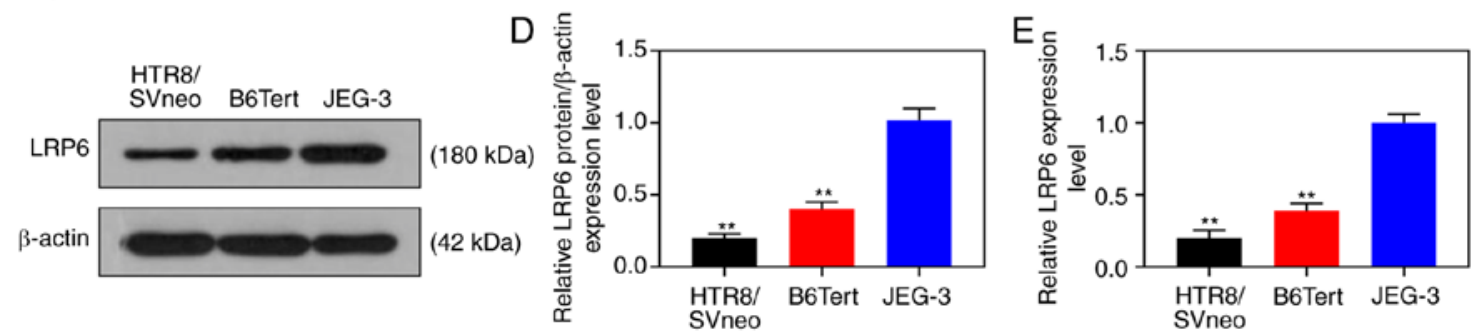

Figure 1. LRP6 is decreased in trophoblast cells. (A) The NCBI database revealed that LRP6 is relatively highly expressed in placental tissues. (B) RT-qPCR assay was performed to measure the expression levels of LRP6 in placental tissues derived from patients with pre-eclampsia and normal pregnant women. (C and D) Western blot analysis was performed to determine LRP6 expression levels in the trophoblast cell lines (B6Tert-1 and HTR8/SVneo) and gestational choriocarcinoma cells (JEG-3). (E) RT-qPCR was performed to determine LRP6 expression levels in the trophoblast cell lines (B6Tert-1 and HTR8/SVneo) and gestational choriocarcinoma cells (JEG-3). ${ }^{* *} \mathrm{P}<0.001$ vs. normal or JEG-3. LRP6, low-density-lipoprotein receptor-related protein 6.

A

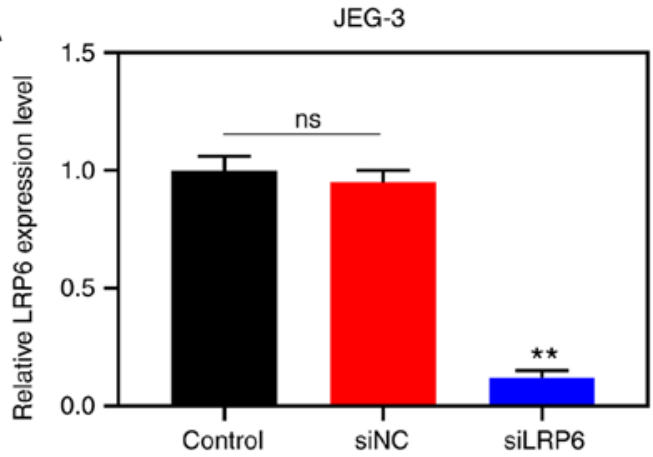

C

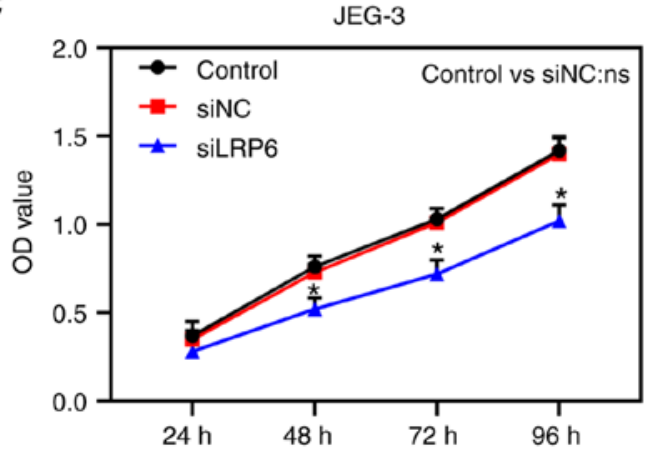

B

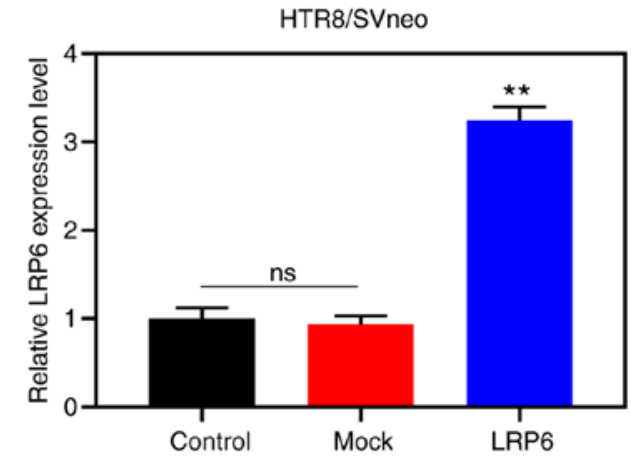

D

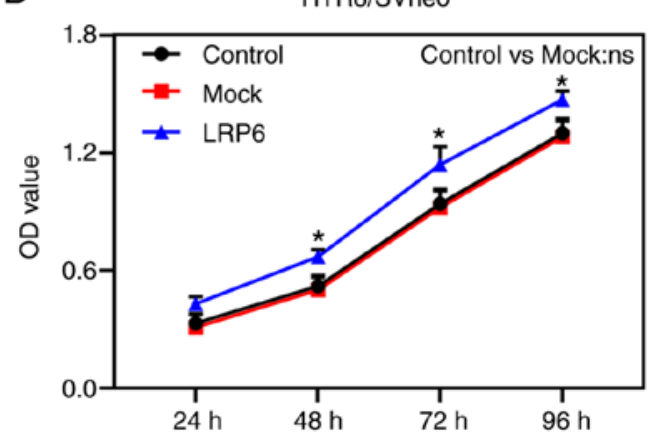

Figure 2. Overexpression of LRP6 enhances the proliferation of trophoblast cells. Negative control (siNC) and siLRP6 were transfected into JEG-3 cells, whereas HTR8/SVneo cells were transfected with LRP6 or empty pcDNA3.1 vector (Mock), and untransfected cells served as the control for comparison. (A and B) Quantitative RT-qPCR assay was performed to measure the expression of LRP6 in the cells. (C and D) Cell Counting Kit-8 (CCK-8) assay was used to measure the cell activity after transfection. ${ }^{* *} \mathrm{P}<0.001,{ }^{*} \mathrm{P}<0.05$ vs. siNC or Mock ( $\mathrm{n}=3$ ). ns, not significant; LRP6, low-density-lipoprotein receptor-related protein 6. 

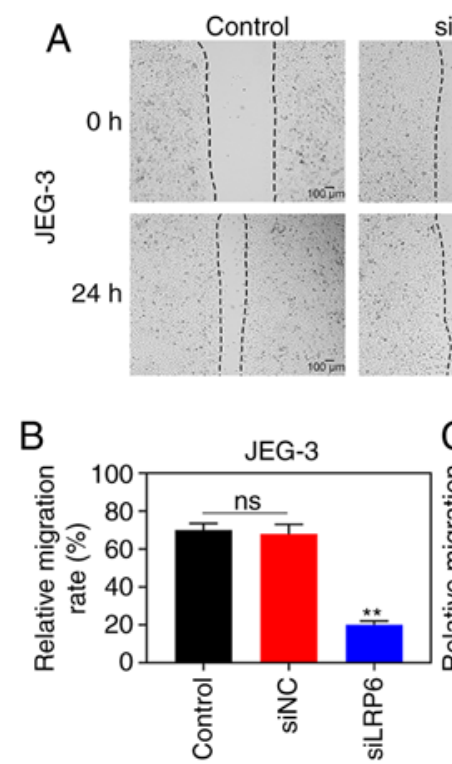

C
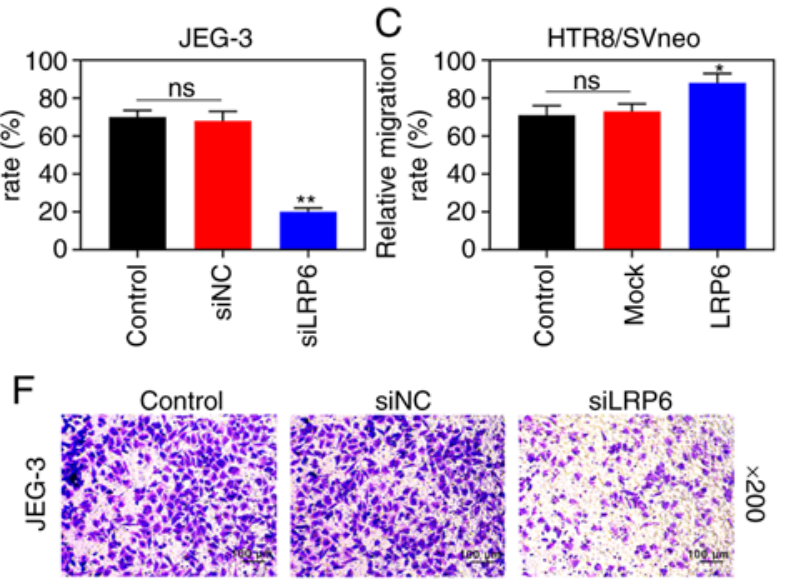

siLRP6

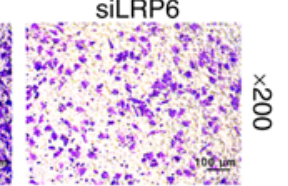

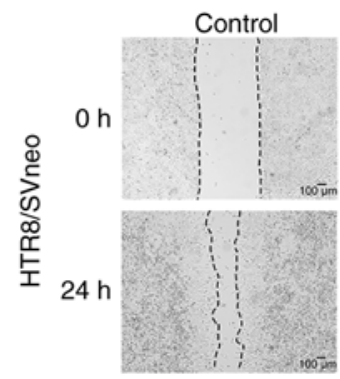
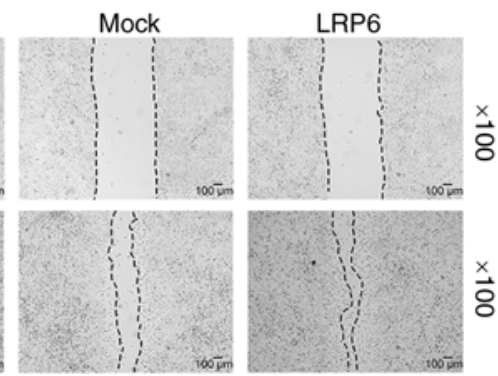

D
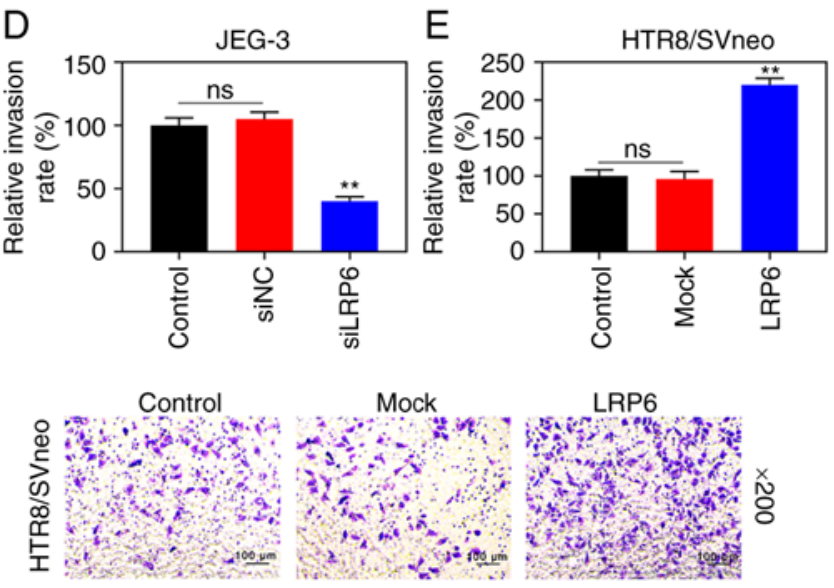
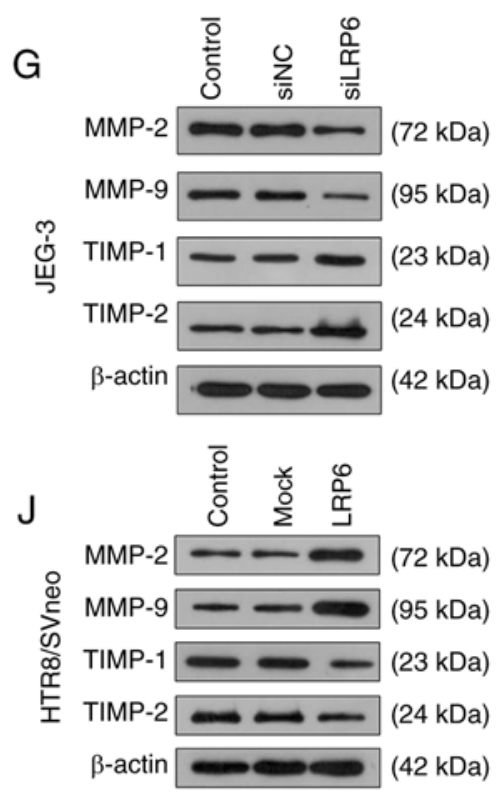

$\mathrm{H}$

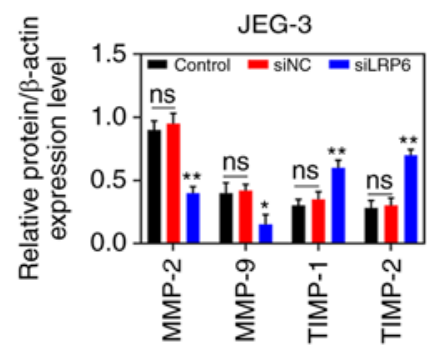

$\mathrm{K}$

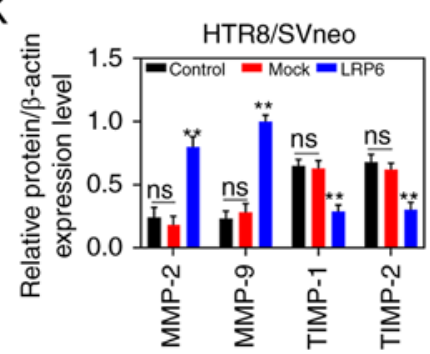

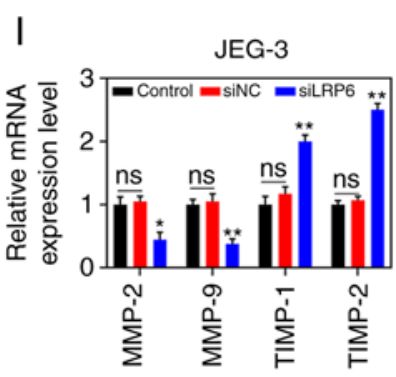

L

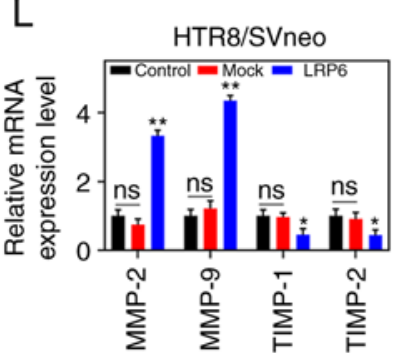

Figure 3. Overexpression of LRP6 enhances migration and invasion of trophoblast cells. Negative control (siNC) and siLRP6 were transfected into JEG-3 cells, whereas HTR8/SVneo cells were transfected with LRP6 or empty pcDNA3.1 vector (Mock), and un-transfected cells served as a control for comparison. (A-F) Microscopic images and quantitative analysis of wound healing and Transwell assays in cells following transfection. (G-L) Western blot analysis and RT-qPCR analyses were performed to determine the expression levels of genes and proteins associated with migration and invasion (i.e., MMP-2, MMP-9, TIMP-1, TIMP-2). The magnification of the images (either $\mathrm{x} 100$ or $\mathrm{x} 200$ ) is indicated in the Figure parts, where applicable. ${ }^{* *} \mathrm{P}<0.001,{ }^{\prime \prime} \mathrm{P}<0.05 \mathrm{vs}$. siNC or Mock (n=3). ns, not significant; LRP6, low-density-lipoprotein receptor-related protein 6; MMP, matrix metalloproteinase; TIMP, tissue inhibitor of metalloproteinase.

( $\mathrm{P}<0.001$; Fig. 1B). As for the cell experiments, compared with the JEG-3 gestational choriocarcinoma cells, LRP6 was weakly expressed in the trophoblast cell lines, B6Tert-1 and HTR8/SVneo ( $\mathrm{P}<0.001$; Fig. 1C-E).

Overexpression of LRP6 promotes the proliferation, migration and invasion of trophoblast cells. Transfection results demonstrated that LRP6 expression was successfully inhibited in JEG-3 cells, although it was clearly upregulated in HTR8/SVneo cells $(\mathrm{P}<0.001$; Fig. 2A and $\mathrm{B})$, suggesting that the transfection had been successfully conducted. In the subsequent experiments, according to the CCK- 8 assay, siLRP6 inhibited the activity of JEG-3 cells, whereas overexpressed LRP6 promoted the cell activity of the HTR8/SVneo 
A

$\begin{array}{lll}\begin{array}{l}\text { Position 99-105 of LRP6 3'UTR } \\ \text { 5' }\end{array} & \text {...AUUAGAGAAGGAUGAGGCAGACC... } \\ \text { hsa-miR-346 } & \text { 3' } & \text { UCUCCGUCCGUACGCCCGUCUGU }\end{array}$

B
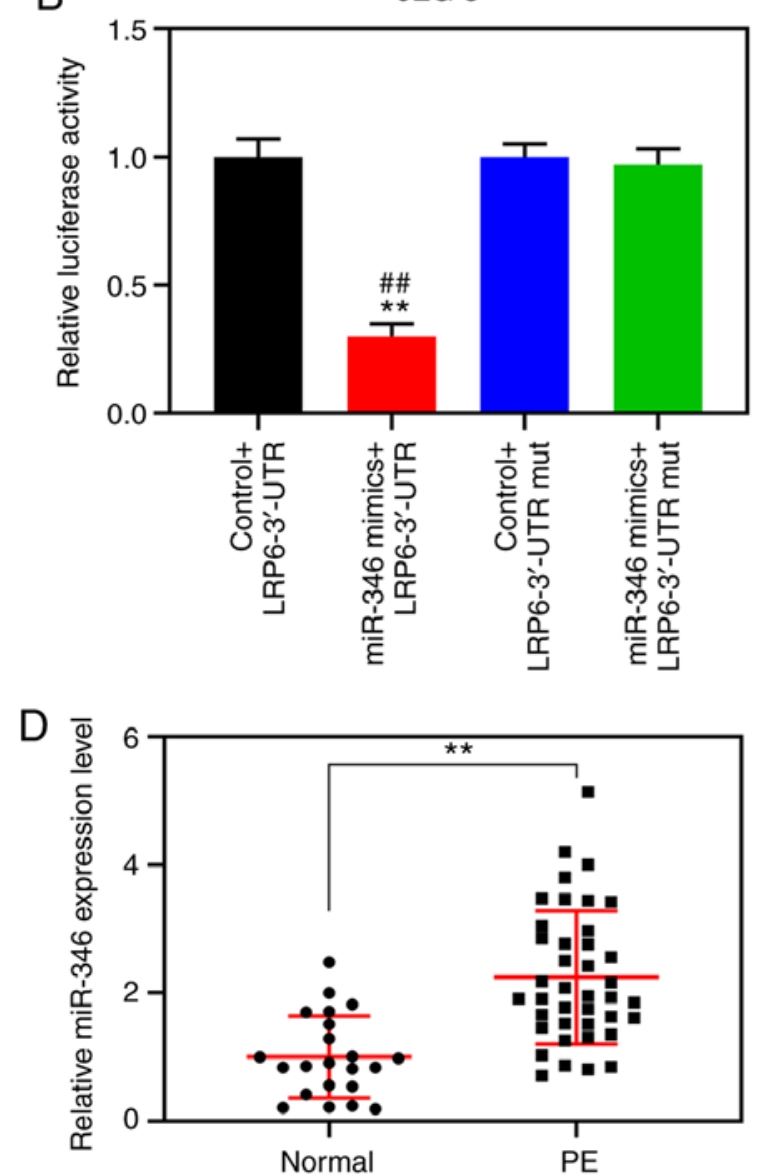

C

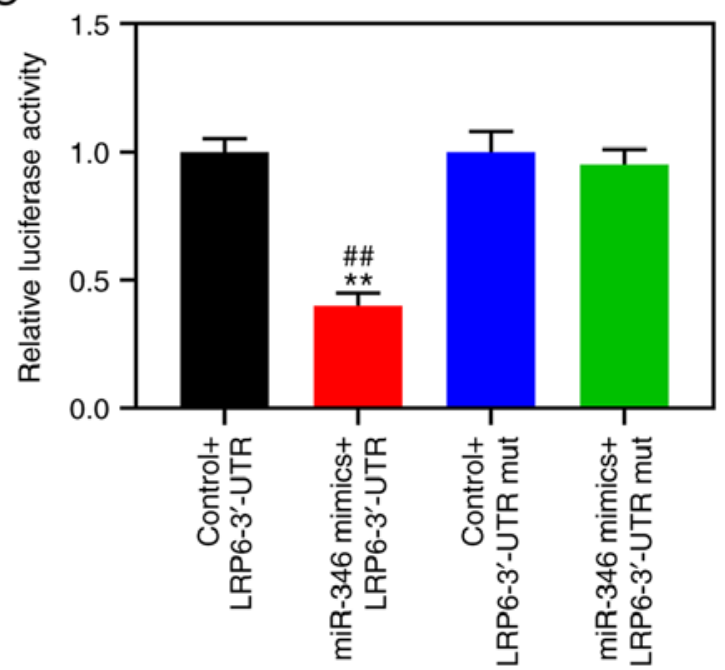

E

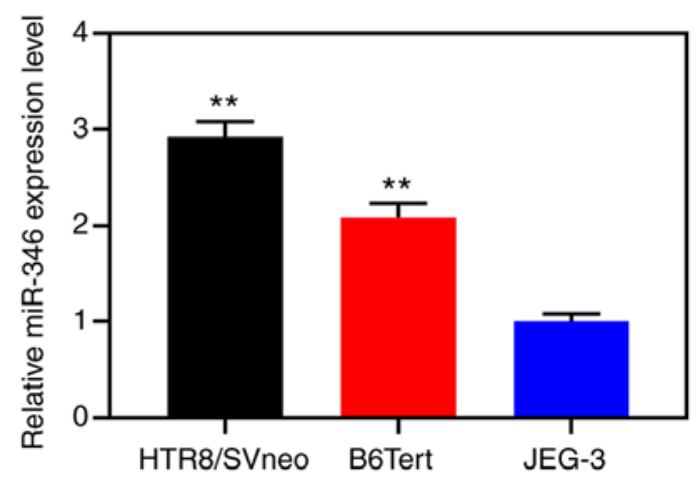

Figure 4. LRP6 is the target gene for miR-346. (A) TargetScan predicted that the nt positions 99-105 of the LRP6 3'-UTR could bind to miR-346. miR-346 mimics or blank control were co-transfected into HTR8/SVneo and JEG-3 cells with the constructed carriers containing wild-type or mut LRP6 3'-UTR. (B and C) Double-luciferase reporter analysis was performed to determine the luciferase activity of cells following co-transfection. (D) RT-qPCR was performed to detect miR-346 expression in the placentas of patients with PE and normal pregnant controls. (E) RT-qPCR was performed to detect the level of miR-346 expression in trophoblastic cells. ${ }^{* *} \mathrm{P}<0.001$ vs. Control + LRP6-3'-UTR; ${ }^{* \#} \mathrm{P}<0.001$ vs. miR-346 mimics + LRP6-3'-UTR mut ( $\mathrm{n}=3$ ). mut, mutant; 3'-UTR, 3'-untranslated region; LRP6, low-density-lipoprotein receptor-related protein 6.

cell lines $(\mathrm{P}<0.05$; Fig. 2C and D). Moreover, microscopic images and quantitative analysis revealed that overexpressed LRP6 led to a measurable increase in the migratory distance and invasion rate of the HTR8/SVneo cells, while the effects of poorly expressed LRP6 on JEG-3 cells followed an opposite trend $(\mathrm{P}<0.05$; Fig. 3A-D). Furthermore, the RT-qPCR and WB analyses revealed that upregulating LRP6 led to promotion of the expression levels of MMP-2 and MMP-9, although the expression levels of TIMP-1 and TIMP-2 in HTR8/SVneo cells were suppressed. Again, it was noted that the effects of siLRP6 on JEG-3 cells followed an opposite trend compared with the effects of overexpressed LRP6 (P<0.001; Fig. 3G-L).

Downregulated miR-346 promotes the proliferation, migration and invasion of trophoblast cells. According to the
TargetScan prediction, nt positions 99-105 of the LRP6 3'-UTR are able to bind to miR-346 (Fig. 4A). For further verification, double-luciferase reporter analysis was performed, and the data demonstrated that luciferase activity was notably inhibited in cells co-transfected with miR-346 and the LRP6 3'-UTR ( $\mathrm{P}<0.001$; Fig. 4B and C). RT-qPCR was subsequently performed to detect miR-346 expression in the placenta of patients with PE and normal pregnant women and trophoblastic cells, and the results showed that the expression level of miR-346 in placental tissues derived from the PE patients was measurably increased compared with that from normal pregnant women $(\mathrm{P}<0.001$; Fig. 4D). Moreover, compared with the JEG-3 gestational choriocarcinoma cells, miR-346 was highly expressed in the trophoblast cell lines, B6Tert-1 and HTR8/SVneo $(\mathrm{P}<0.001$; Fig. 4E). Following transfection, miR-346 was shown to be highly expressed in JEG-3 
A
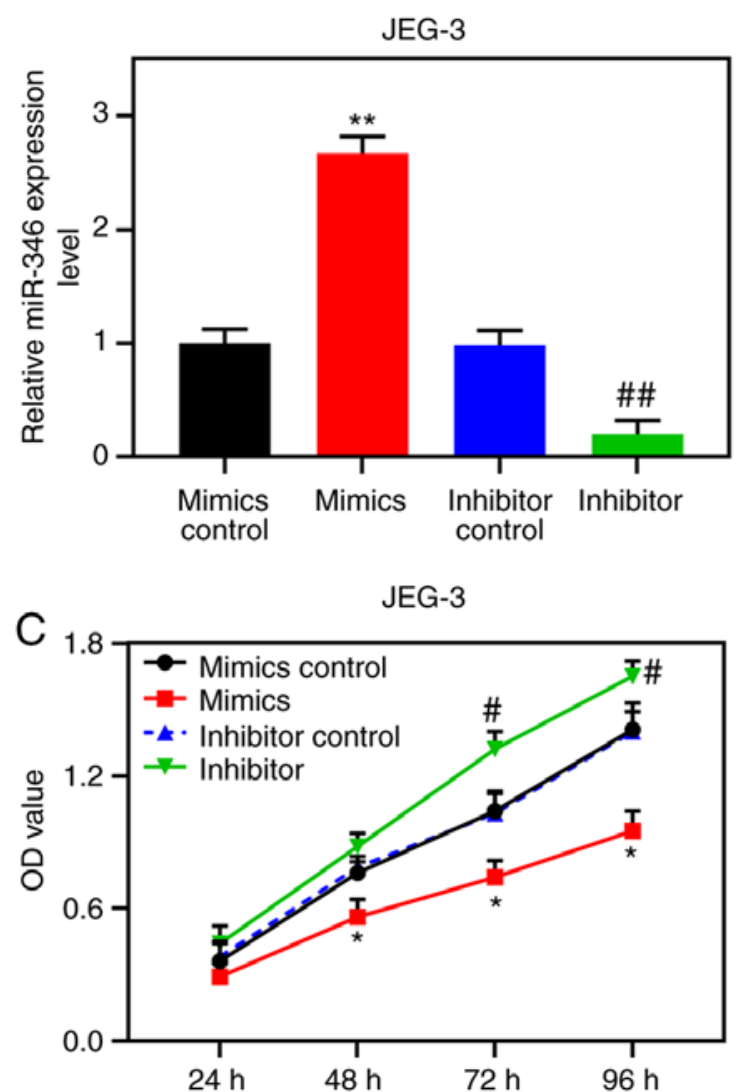

B
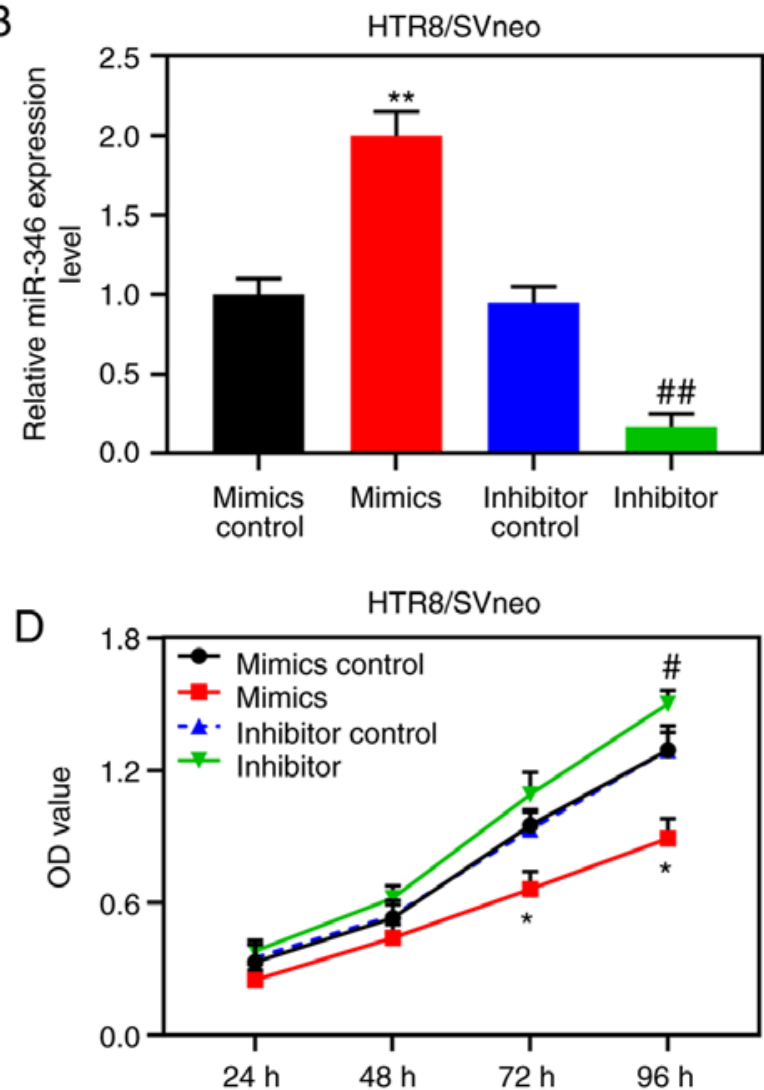

Figure 5. Downregulated miR-346 promotes the proliferation of trophoblast cells. Mimics control, miR-346 mimics, inhibitor control, and miR-346 inhibitor were respectively transfected into HTR8/SVneo and JEG-3 cells. (A and B) RT-qPCR assay was performed to measure the expression of LRP6 in the transfected cells. (C and D) CCK-8 assay was performed to detected cell activity after transfection. ${ }^{* *} \mathrm{P}<0.001 ;{ }^{*} \mathrm{P}<0.05$ vs. mimics control; ${ }^{\# \#} \mathrm{P}<0.001 ;{ }^{*} \mathrm{P}<0.05$ vs. Inhibitor control $(n=3)$. OD, optical density.

cells, and poorly expressed in HTR8/SVneo cells $(\mathrm{P}<0.001$; Fig. 5A and B). CCK-8 assays confirmed that upregulated miR-346 led to suppression of the activity of the HTR8/SVneo cells, whereas poorly expressed miR-346 increased the activities of these cells (Fig. 5C and D).

Wound healing and Transwell experiments were subsequently performed. The results revealed that upregulated miR-346 reduced the cell migration distance and reduced invasion rates of the JEG-3 and HTR8/SVneo cells, whereas downregulating miR-346 resulted in increased rates of cell migration and invasion $(\mathrm{P}<0.05$; Fig. 6$)$. Accordingly, RT-qPCR and WB analysis revealed that upregulated miR-346 could increase the expression levels of TIMP-1 and TIMP-2, although the expression levels of MMP-2 and MMP-9 in the two cell lines were decreased, and these results showed the opposite trend to those performed with downregulated miR-346 ( $\mathrm{P}<0.05$; Fig. 7A-F).

LRP6 reverses the inhibitory effect of miR-346 on the proliferation, migration and invasion of trophoblast cells. According to the results of RT-qPCR and WB analysis, the expression level of LRP6 was gradually downregulated by the upregulation of miR-346, but it was markedly upregulated by downregulating miR-346 ( $\mathrm{P}<0.05$; Fig. 7G-L). After the co-transfection, CCK-8 assays revealed that siLRP6 could reverse the effects of poorly expressed miR-346 on JEG-3 cell activity, whereas LRP6 could reverse the inhibitory effect of overexpressed miR-346 on HTR8/SVneo cell activity (Fig. 8A and B). Furthermore, the experimental images and quantitative analysis from wound healing and Transwell experiments indicated that siLRP6 suppressed the effects of poorly expressed miR-346 on cell migration and invasion, whereas LRP6 overexpression relieved the inhibitory effects of overexpressed miR-346 on cell migration and invasion $(\mathrm{P}<0.05$; Fig. 8C-J). In addition, the expression levels of LRP6 were significantly downregulated in HTR8/SVneo cells that were transfected with miR-346 mimics $(\mathrm{P}<0.05$; Fig. 9).

\section{Discussion}

Embryo implantation, which is one of the decisive factors for a successful pregnancy, refers to the process of the embryo gradually burying itself in the endometrial epithelium after entering the uterine cavity, and the invasion of trophoblast cells has a crucially important role during the process (13). Trophoblast cells are the main cell type in placental tissues, and abnormal migration and invasion abilities of the cells leads to the occurrence of PE, gestational choriocarcinoma and/or other related diseases $(14,15)$. In the present study, it has been shown that LRP6 was suppressed in PE tissues and different trophoblast cell lines, although it was expressed at relatively high levels in gestational choriocarcinoma cells. In a previously published study, Wang et al (16) demonstrated that downregulated LRP6 could inhibit the growth, invasion and 
A
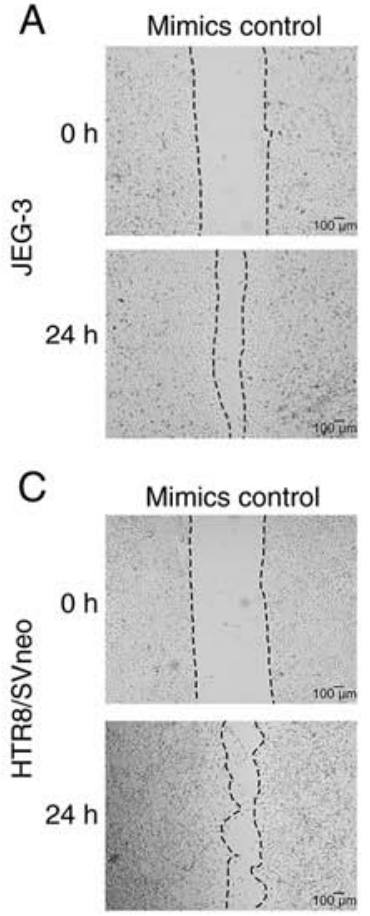

E

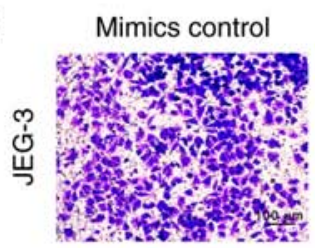

Mimics

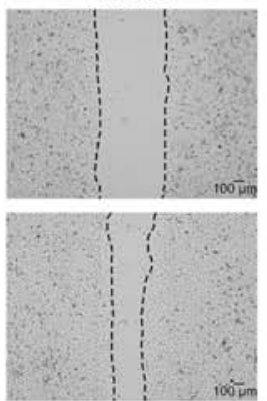

Mimics

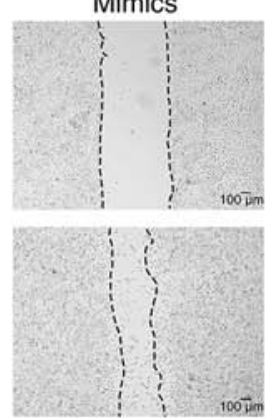

Mimics

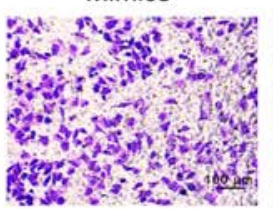

Inhibitor control

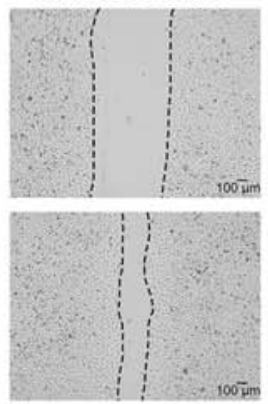

Inhibitor control
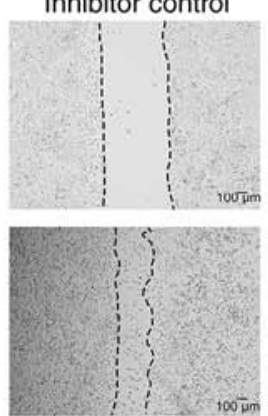

Inhibitor control

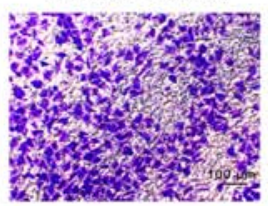

Inhibitor

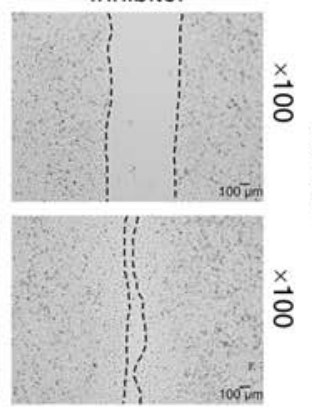

Inhibitor

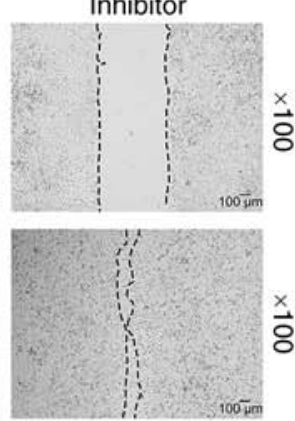

B

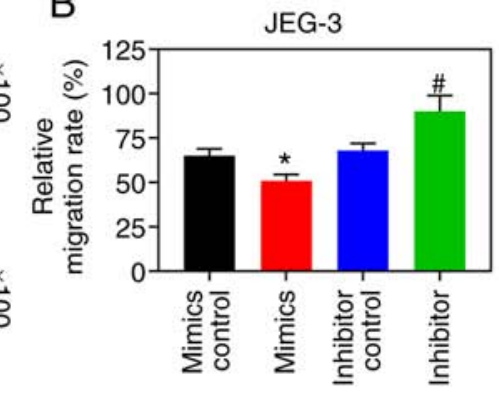

D
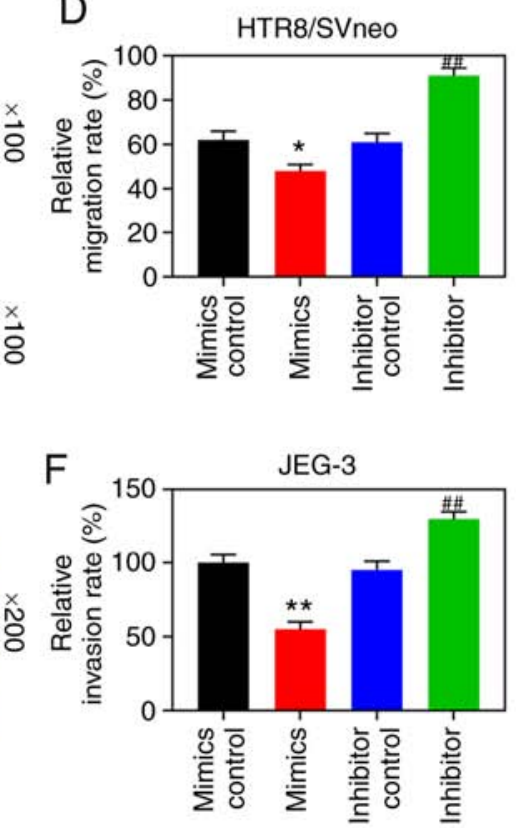

Inhibitor

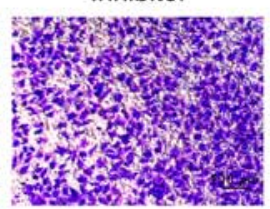

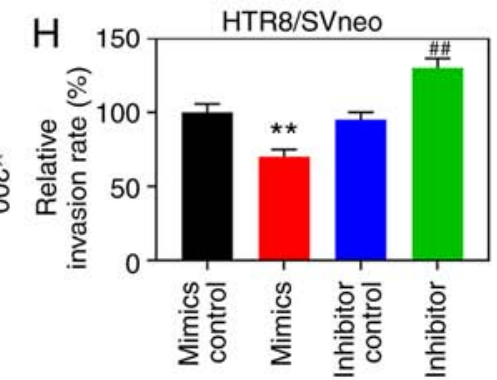

Figure 6. Downregulated miR-346 promotes migration and invasion of trophoblast cells. Mimics control, miR-346 mimics, inhibitor control, and miR-346 inhibitor were respectively transfected into the HTR8/SVneo and JEG-3 cells. Microscopic images and quantitative analysis of (A-D) wound healing and $(\mathrm{E}-\mathrm{H})$ Transwell assays in cells following transfection. The magnification of the images (either x100 or x200) is indicated in the Figure parts, where applicable. ${ }^{* *} \mathrm{P}<0.001 ;{ }^{*} \mathrm{P}<0.05$, vs. mimics control; ${ }^{\# \#} \mathrm{P}<0.001 ;{ }^{\#} \mathrm{P}<0.05$ vs. inhibitor control $(\mathrm{n}=3)$.

migration of retinoblastoma cells, findings that were similar to the results in the current study. Oppositely to the effect of downregulated LRP6, the present study has also demonstrated that overexpressing LRP6 can measurably promote cell activity and enhance the migration distance and the invasion rate of trophoblast cells, suggesting that upregulated LRP6 may slow down the progression of PE. As for the role of LRP6 in other diseases, Mao et al (17) demonstrated that LRP6 was upregulated in human triple negative breast cancer cell lines, and the metastatic ability of the cancer cells was increased via the Wnt/ $\beta$-catenin protein signaling pathway. LRP6 was also found to promote metastasis and invasion of colorectal cancer through cytoskeleton dynamics (18). These findings further confirmed the role exerted by LRP6 overexpression in terms of promoting cell proliferation, migration and invasion, and therefore LRP6 may be a potential therapeutic target for treating trophoblast-cell-associated diseases.

Degradation of the extracellular matrix by members of the MMP family is a critical process in cell migration and invasion (19). TIMPs are a type of tissue inhibitor of metalloproteinases with multiple physiological functions, and they are able to bind with MMPs noncovalently to maintain the activity of MMPs, and to participate in the maintenance and stability of extracellular matrix components (20). On 

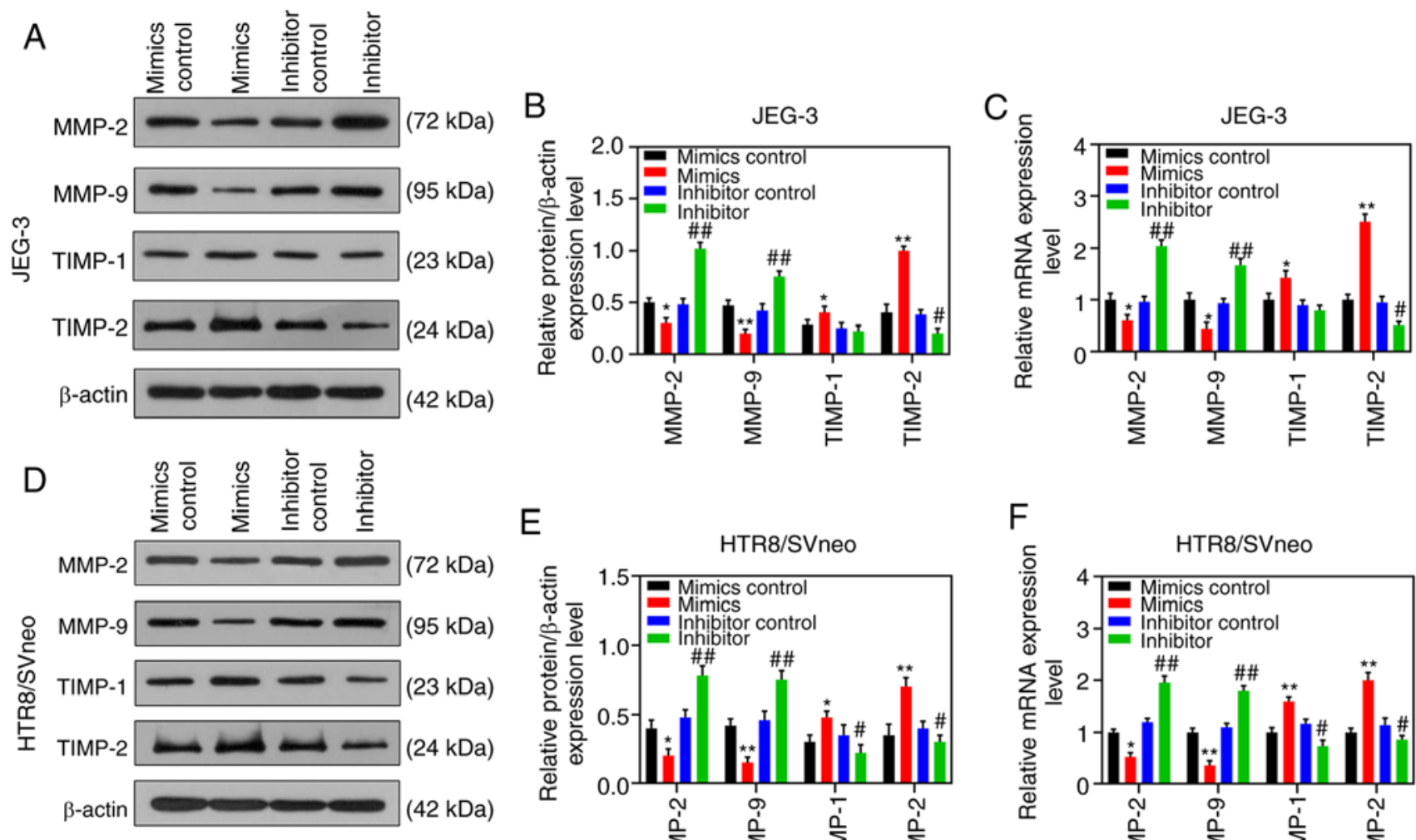

\section{$\mathrm{E}$}
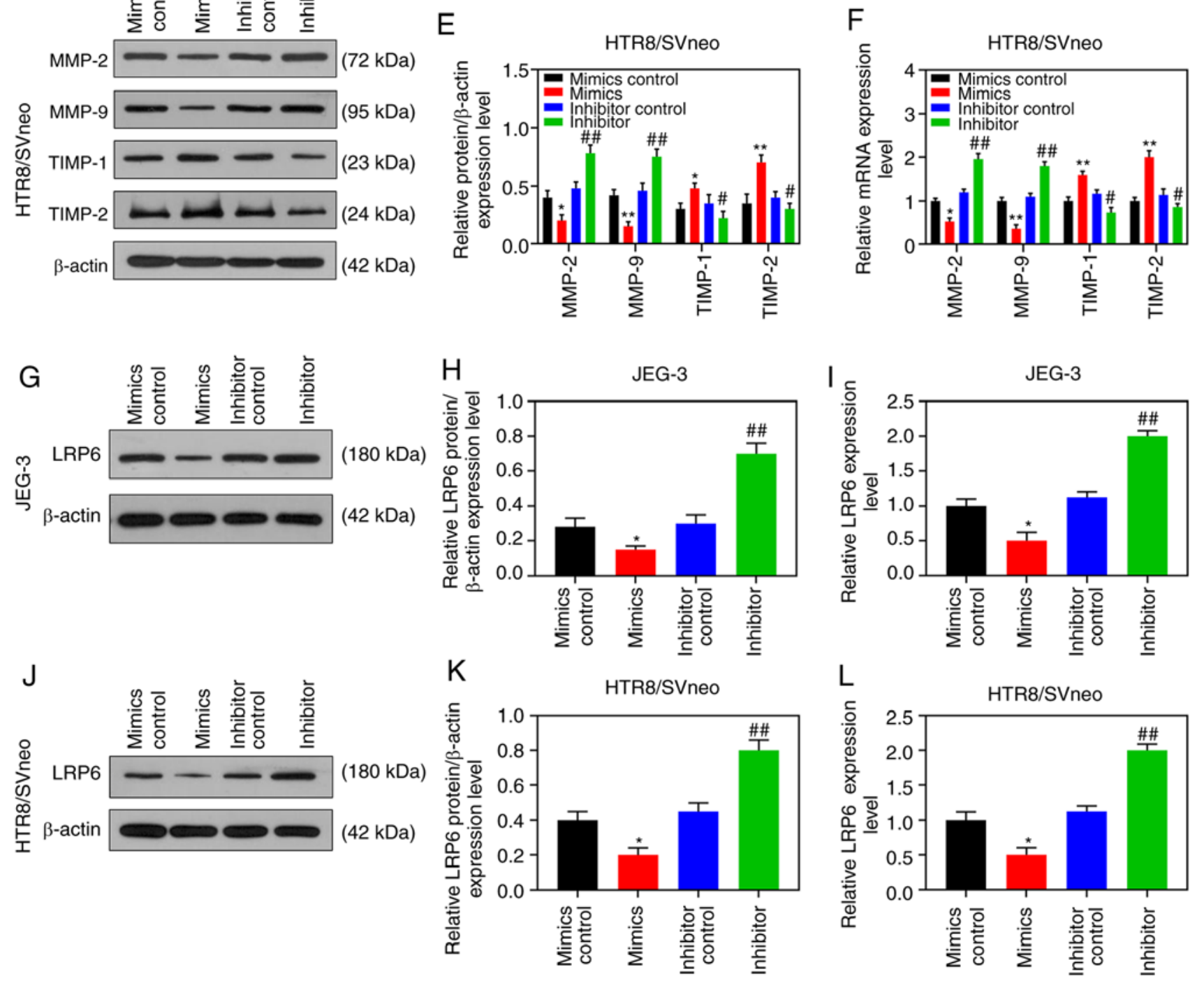

Figure 7. Downregulated miR-346 promotes the expressions of genes and proteins associated with migration and invasion. Mimics control, miR-346 mimics, inhibitor control, and miR-346 inhibitor were respectively transfected into HTR8/SVneo and JEG-3 cells. (A-F) Western blot and RT-qPCR analyses were performed to determine the expression levels of genes and proteins associated with migration and invasion (MMP-2, MMP-9, TIMP-1, TIMP-2). (G-L) Western blotting and RT-qPCR assays were used to determine the expression levels of LRP6 following transfection. ${ }^{* *} \mathrm{P}<0.001$; ${ }^{*} \mathrm{P}<0.05$ vs. mimics control; ${ }^{\# \#} \mathrm{P}<0.001$; ${ }^{\#} \mathrm{P}<0.05$ vs. inhibitor control ( $\left.\mathrm{n}=3\right)$. LRP6, low-density-lipoprotein receptor-related protein 6; MMP, matrix metalloproteinase; TIMP, tissue inhibitor of metalloproteinase.

the one hand, MMP-2 and MMP-9 degrade the extracellular matrix, allowing trophoblast cells to continuously invade the endometrium with the gradual formation of chorion, which eventually allows trophoblast cells to penetrate the decidua and blood vessels during placental formation $(21,22)$. On the other hand, specific binding of TIMP-1 to MMP-9, and of TIMP-2 to MMP-2, inhibits the invasion of MMPs, so that the invasive behavior and proliferation of trophoblast cells can 

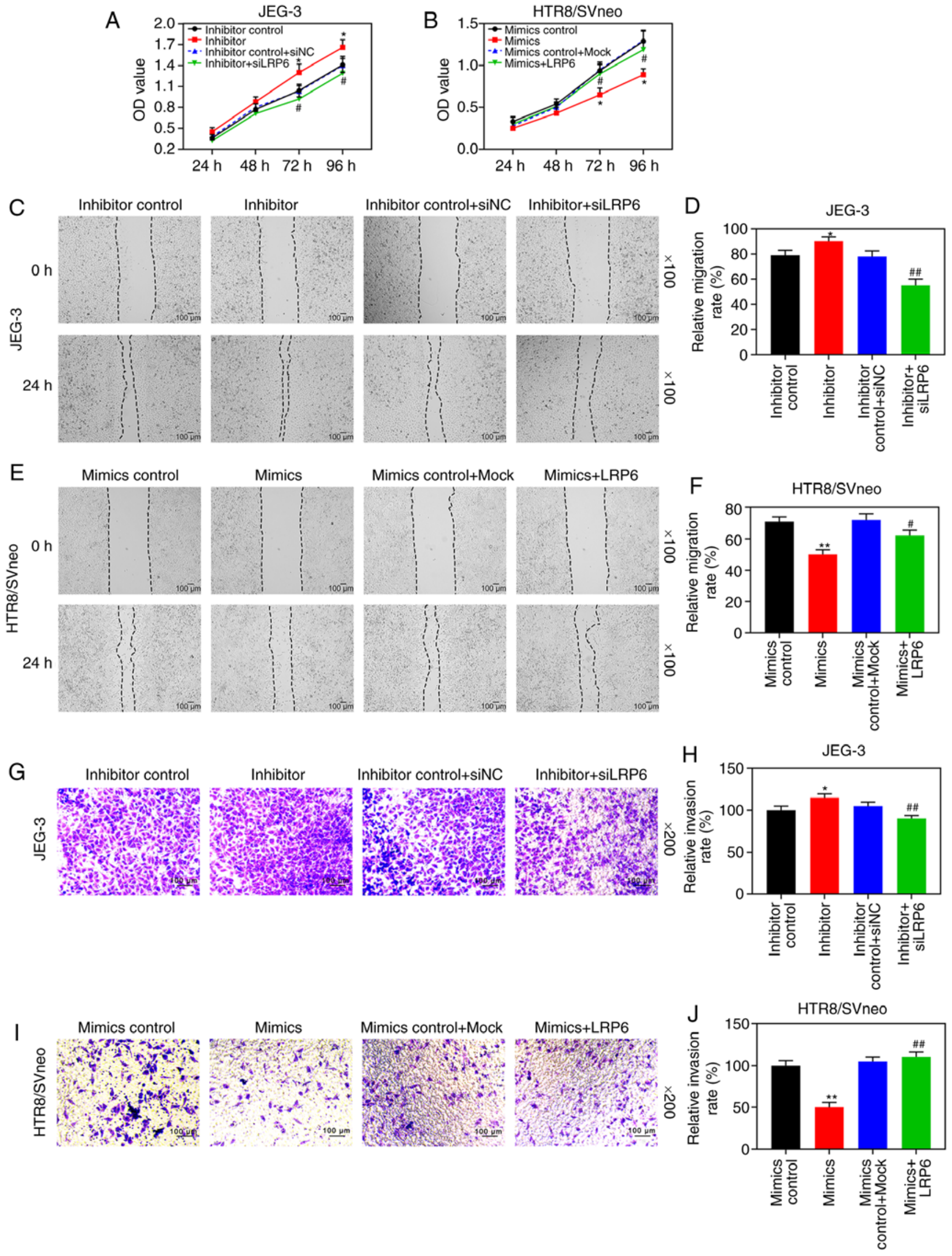

Figure 8. LRP6 reverses the inhibitory effect of miR-346 on the activity, migration and invasion of trophoblast cells. JEG-3 cells were transfected with inhibitor control, miR-346 inhibitor, inhibitor control + mock, and inhibitor + siLRP6, whereas HTR8/SVneo cells were transfected with mimics control, miR-346 mimics, mimics control + mock, and mimics + LRP6. (A and B) CCK-8 assays were performed to detect the cell activity following transfection. Microscopic images and quantitative analysis of (C-F) wound healing and (G-J) Transwell assays in the cells following transfection. The magnification of the images (either $\mathrm{x} 100$ or $\mathrm{x} 200$ ) is indicated in the Figure parts, where applicable. ${ }^{* *} \mathrm{P}<0.001 ;{ }^{*} \mathrm{P}<0.05$ vs. inhibitor control or mimics control; ${ }^{* \#} \mathrm{P}<0.001$; ${ }^{*} \mathrm{P}<0.05$ vs. inhibitor or $\operatorname{mimics}(\mathrm{n}=3)$. 

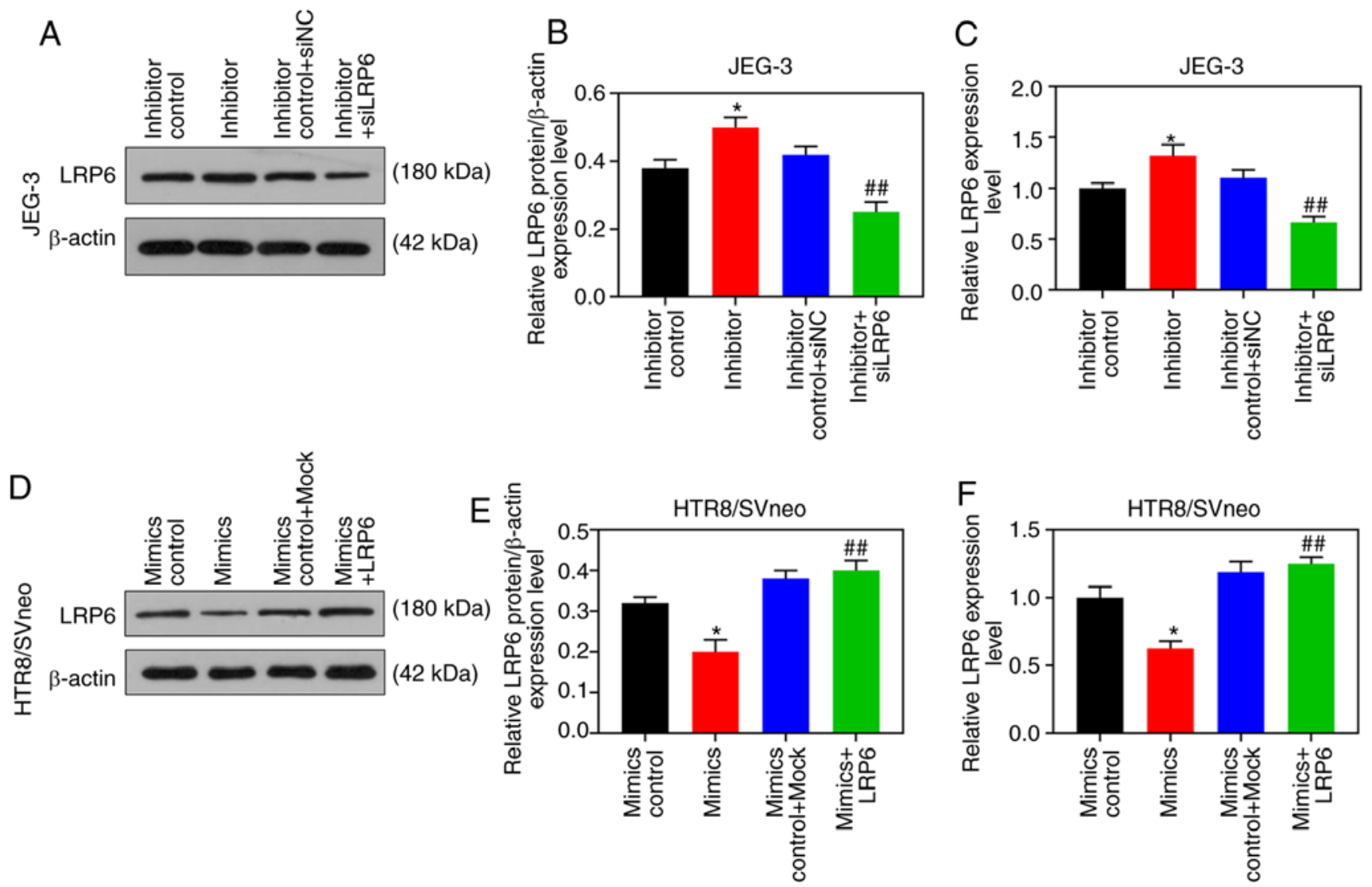

Figure 9. miR-346 inhibits the expression of LRP6 in trophoblast cells. (A-C) JEG-3 cells were transfected with inhibitor control, miR-346 inhibitor, inhibitor control + mock, and inhibitor + siLRP6; (D-F) HTR8/SVneo cells were transfected with mimics control, miR-346 mimics, mimics control + mock, and mimics + LRP6. Western blot and RT-qPCR analyses were performed to determine the expression level of LRP6 in the transfected cells. "P<0.05 vs. inhibitor control or mimics control; ${ }^{\# /} \mathrm{P}<0.001$ vs. inhibitor or mimics $(\mathrm{n}=3)$. LRP6, low-density-lipoprotein receptor-related protein 6.

be properly controlled, thereby leading to the maintenance of moderate levels of cell invasion (23). The present study has shown that overexpression of LRP6 not only promoted the expression of MMP-2 and MMP-9, but also inhibited the secretion of TIMP-1 and TIMP-2, in trophoblast cells, whereas transfection with siLRP6 led to entirely the opposite effects on gestational choriocarcinoma cells. These results suggest that the upregulation of LRP6 may control cell migration and invasion by regulating the expression levels of MMPs and TIMPs, thereby alleviating the conditions of PE and gestational choriocarcinoma.

miRNAs have been demonstrated to be involved in embryo implantation through regulating target genes $(24,25)$. miRNAs control the expression of target genes, and $60 \%$ of them are predicted to be regulators of protein-encoding genes in humans (26). Our study demonstrated that miR-346 is able to target and negatively regulate the expression of LRP6, suggesting that upregulated miR-346 inhibited LRP6 expression. Moreover, miR-346 was highly expressed in tissues and trophoblast cell lines; the gestational choriocarcinoma cell line JEG-3 served as a control. LRP6 is known to promote metastasis in numerous types of cancer; however, to the best of our knowledge, there are no reports of its role in trophoblasts. Therefore, JEG-3 cells were selected as a control group to study the effect of LRP6 on the normal trophoblast cell line B6Tert-1. In addition, the current study has demonstrated that overexpressed miR-346 is able to suppress the proliferation, migration and invasion of trophoblast cells and JEG-3 cell, a finding that was reversed by LRP6. Similarly, the downregulation of miR-346 led to an activation of the proliferation, migration and invasion of gestational choriocarcinoma cells, and this phenomenon was also be reversed by siLRP6 treatment. miR-346 is known to have a tumor-promoter function in a variety of tumor cells, including in liver cancer (27), nasopharyngeal cancer (28), and breast cancer (29). However, contrary to previous findings, the present study revealed that downregulated miR-346 promoted the proliferation, migration and invasion of trophoblast cells. It was speculated that miR-346 might have cell-specific effects; therefore, miR-346 may have different effects on various cell types. In addition, miR-346 inhibited migration and invasion of HTR8/SVneo cells. Therefore, it is possible to conclude that miR-346 was involved in the proliferation, migration and invasion of the trophoblast cells, suggesting that miR-346 may also have a critical role in PE and gestational choriocarcinoma.

Furthermore, Su et al (30) reported that miR-346 regulated endocrine gland-vascular endothelial growth factor (EG-VEGF)-induced trophoblast invasion by inhibiting MMP-2 and MMP-9, although it had only a limited effect on TIMP-1 and TIMP-2. Consistently in the present study, it was found that the effect of downregulated miR-346 on invasion-associated enzymes was similar to that of upregulated LRP6, which was found to promote the expression of 
MMP-2 and MMP-9 and to inhibit the expression of TIMP-1 and TIMP-2. Taken together, these results suggested that the effects of miR-346 on cell migration and invasion are mainly realized by regulating the expression of MMPs and inhibiting TIMPs.

In conclusion, the present study has demonstrated that LRP6 is downregulated in patients with PE, whereas the upregulation of LRP6 promoted the proliferation and migration of trophoblast cells, which is opposite to the effect of downregulated LRP6 in gestational choriocarcinoma cells. Moreover, LRP6 has been shown to be involved in the occurrence of PE and gestational choriocarcinoma through regulating the activity, migratory and invasive abilities of cancer cells through miR-346, suggesting that LRP6 might be a possible therapeutic target for the treatment of PE and gestational choriocarcinoma, and that a putative therapy involving LRP6 treatment may decelerate the disease process. However, the effect of miR-346 on the invasion and proliferation of trophoblast cells will be further confirmed in our future studies. In addition, the expression of LRP6 in tissues of patients with choriocarcinoma needs to be investigated further. Furthermore, in vivo animal experiments should also help in subsequent investigations of the expression levels of LRP6, and its effects, in animals.

\section{Acknowledgements}

Not applicable.

\section{Funding}

No funding was received.

\section{Availability of data and materials}

The datasets used and/or analyzed during the current study are available from the corresponding author on reasonable request.

\section{Authors' contributions}

LZ made the most substantial contributions to the paper in terms of its conception and design of the experiments; HL, ML, WZ, ZY, and SZ were involved with data acquisition, data analysis and interpretation; and LZ was responsible for drafting the article and critically revising it for important intellectual content. All authors have approved the final approval of the version, and agree to be held accountable for all aspects of the work in ensuring that questions related to the accuracy or integrity of the work are appropriately investigated and resolved.

\section{Ethics approval and consent to participate}

All procedures performed in studies involving human participants were in accordance with the ethical standards of the institutional and/or national research committee, and with the 1964 Helsinki declaration and its later amendments or comparable ethical standards. Specifically, the present study was approved by the Ethics Committee of Qilu Hospital of Shandong University (grant approval number: SDUQLH20180121), and the informed consent from all participants was obtained.

\section{Patient consent for publication}

Not applicable.

\section{Competing interests}

The authors declare they have no conflicts of interests.

\section{References}

1. Turner K and Hameed AB: Hypertensive disorders in pregnancy current practice review. Curr Hypertens Rev 13: 80-88, 2017.

2. Mol BWJ, Roberts CT, Thangaratinam S, Magee LA, de Groot CJM and Hofmeyr GJ: Pre-eclampsia. Lancet 387: 999-1011, 2016.

3. von Dadelszen P and Magee LA: Pre-eclampsia: An update. Curr Hypertens Rep 16: 454, 2014

4. Zakiyah N, Postma MJ, Baker PN and van Asselt AD; IMPROvED Consortium: Pre-eclampsia diagnosis and treatment options: A review of published economic assessments. Pharmacoeconomics 33: 1069-1082, 2015.

5. Robins JC: Implantation: Trophoblast-endometrial interactions. Semin Reprod Med 34: 3-4, 2016.

6. Gupta SK, Malhotra SS, Malik A, Verma S and Chaudhary P: Cell signaling pathways involved during invasion and syncytialization of trophoblast cells. Am J Reprod Immunol 75: 361-371, 2016.

7. McNally R, Alqudah A, Obradovic D and McClements L: Elucidating the pathogenesis of pre-eclampsia using in vitro models of spiral uterine artery remodelling. Curr Hypertens Rep 19: 93, 2017.

8. Zhang Y, Hu X, Gao G, Wang Y, Chen P and Ye Y: Autophagy protects against oxidized low density lipoprotein-mediated inflammation associated with preeclampsia. Placenta 48: 136-143, 2016.

9. Arifin R, Kyi WM, Che Yaakob CA and Yaacob NM: Increased circulating oxidised low-density lipoprotein and antibodies to oxidised low-density lipoprotein in preeclampsia. J Obstet Gynaecol 37: 580-584, 2017.

10. Liu CC, Prior J, Piwnica-Worms D and Bu G: LRP6 overexpression defines a class of breast cancer subtype and is a target for therapy. Proc Natl Acad Sci USA 107: 5136-5141, 2010.

11. Ramos JGL, Sass N and Costa SHM: Preeclampsia. Rev Bras Ginecol Obstet 39: 496-512, 2017.

12. Rao X, Huang X, Zhou Z and Lin X: An improvement of the $2^{\wedge}($-delta delta CT) method for quantitative real-time polymerase chain reaction data analysis. Biostat Bioinforma Biomath 3: 71-85, 2013.

13. Godbole G, Suman P, Malik A, Galvankar M, Joshi N, Fazleabas A, Gupta SK and Modi D: Decrease in expression of HOXA10 in the decidua after embryo implantation promotes trophoblast invasion. Endocrinology 158: 2618-2633, 2017.

14. Li P, Guo W, Du L, Zhao J, Wang Y, Liu L, Hu Y and Hou Y: microRNA-29b contributes to pre-eclampsia through its effects on apoptosis, invasion and angiogenesis of trophoblast cells. Clin Sci (Lond) 124: 27-40, 2013.

15. Chen H, Meng T, Liu X, Sun M, Tong C, Liu J, Wang H and $\mathrm{Du} \mathrm{J}$ : Long non-coding RNA MALAT-1 is downregulated in preeclampsia and regulates proliferation, apoptosis, migration and invasion of JEG-3 trophoblast cells. Int J Clin Exp Pathol 8: 12718-12727, 2015.

16. Wang J, Wang X, Li Z, Liu H and Teng Y: MicroRNA-183 suppresses retinoblastoma cell growth, invasion and migration by targeting LRP6. FEBS J 281: 1355-1365, 2014.

17. Mao Z, Li H, Du B, Cui K, Xing Y, Zhao X and Zai S: LncRNA DANCR promotes migration and invasion through suppression of lncRNA-LET in gastric cancer cells. Biosci Rep 37: BSR20171070, 2017.

18. Yao Q, An Y, Hou W, Cao YN, Yao MF, Ma NN, Hou L, Zhang H, Liu HJ and Zhang B: LRP6 promotes invasion and metastasis of colorectal cancer through cytoskeleton dynamics. Oncotarget 8: 109632-109645, 2017.

19. Zhong T, Chen J, Ling Y, Yang B, Xie X, Yu D, Zhang D, Ouyang $J$ and Kuang $H$ : Down-regulation of neuropathy target esterase in preeclampsia placenta inhibits human trophoblast cell invasion via modulating MMP-9 levels. Cell Physiol Biochem 45: 1013-1022, 2018. 
20. Arpino V, Brock M and Gill SE: The role of TIMPs in regulation of extracellular matrix proteolysis. Matrix Biol 44-46: 247-254, 2015.

21. Zong L, Wei X, Gou W, Huang P and Lv Y: Zinc improves learning and memory abilities of fetal growth restriction rats and promotes trophoblast cell invasion and migration via enhancing STAT3-MMP-2/9 axis activity. Oncotarget 8: 115190-115201, 2017.

22. Yu Y, Wang L, Liu T and Guan H: MicroRNA-204 suppresses trophoblast-like cell invasion by targeting matrix metalloproteinase-9. Biochem Biophys Res Commun 463: 285-291, 2015.

23. Nissi R, Talvensaari-Mattila A, Kotila V, Niinimaki M, Jarvela I and Turpeenniemi-Hujanen T: Circulating matrix metalloproteinase MMP-9 and MMP-2/TIMP-2 complex are associated with spontaneous early pregnancy failure. Reprod Biol Endocrinol 11: $2,2013$.

24. Zendjabil M, Favard S, Tse C, Abbou O and Hainque B: The microRNAs as biomarkers: What prospects? C R Biol 340: 114-131, 2017 (In French).

25. Liang J, Wang $S$ and Wang Z: Role of microRNAs in embryo implantation. Reprod Biol Endocrinol 15: 90, 2017.

26. Tufekci KU, Oner MG, Meuwissen RL and Genc S: The role of microRNAs in human diseases. Methods Mol Biol 1107: 33-50, 2014.
27. Yu Q, Yang X, Duan W, Li C, Luo Y and Lu S: miRNA-346 promotes proliferation, migration and invasion in liver cancer. Oncol Lett 14: 3255-3260, 2017.

28. Yan HL, Li L, Li SJ, Zhang HS and Xu W: miR-346 promotes migration and invasion of nasopharyngeal carcinoma cells via targeting BRMS1. J Biochem Mol Toxicol 30: 602-607, 2016.

29. Yang F, Luo LJ, Zhang L, Wang DD, Yang SJ, Ding L, Li J, Chen D, Ma R, Wu JZ and Tang JH: MiR-346 promotes the biological function of breast cancer cells by targeting SRCIN1 and reduces chemosensitivity to docetaxel. Gene 600: 21-28, 2017.

30. Su MT, Tsai PY, Tsai HL, Chen YC and Kuo PL: miR-346 and miR-582-3p-regulated EG-VEGF expression and trophoblast invasion via matrix metalloproteinases 2 and 9. Biofactors 43: 210-219, 2017.

(i) (5) This work is licensed under a Creative Common Attribution-NonCommercial-NoDerivatives 4.0 International (CC BY-NC-ND 4.0) License. 